\title{
Más allá de los libros: \\ La Biblioteca Ricardo León y los 17 objetivos de la UNESCO
}

\author{
Marina Cuervo Moreno \\ Biblioteca Municipal Ricardo León de Galapagar, Madrid, España \\ marina.cuervo@galapagar.es \\ Pablo Parra Valero \\ Biblioteca Municipal Ricardo León de Galapagar, Madrid, España \\ pablo.parra@galapagar.es
}

Universidad Complutense, Facultad de Ciencias de la Documentación, Madrid, España

DOI: https://doi.org/10.26512/rici.v12.n2.2019.23736

Recebido/Recibido/Received: 2018-12-18

Aceitado/Aceptado/Accepted: 2019-03-18

Resumen: Este proyecto, desarrollado y ejecutado íntegramente por personal bibliotecario, se concibe para trabajar sobre los 17 Objetivos de Desarrollo Sostenible (ODS) de la UNESCO a través de la lectura, en un programa orientado al colectivo de niños y niñas de entre 5 y 15 años en riesgo de exclusión social. Tras el traslado de la Biblioteca Municipal a una ubicación más céntrica se hacen evidentes las necesidades de colectivos cercanos a la misma y que generalmente no forman parte de los usuarios habituales. Se detecta que la gran mayoría son inmigrantes marroquíes de segunda generación y sus familias muestran carencias en aspectos tales como la comprensión lectora, el uso correcto de las instalaciones de la biblioteca y la interacción con otros usuarios ajenos a su colectivo. Con este proyecto se busca la ruptura de barreras por razones de raza o de religión y se pretende integrar a los colectivos anteriormente mencionados en las actividades del día a día de la biblioteca, también se busca establecer un punto de partida para continuar en esta línea de colaboración y asentar las bases de un proyecto con una proyección más amplia, tanto en el tiempo como en el número de beneficiarios.

Palabras clave: lectura. integración social. Biblioteca pública. Infancia. Jóvenes. animación a la lectura. desarrollo sostenible.

\section{Além dos livros: A Biblioteca Ricardo León e os 17 objetivos da UNESCO}

Resumo: Projeto desenvolvido e executado inteiramente pela equipe da biblioteca que foi concebido para trabalhar nos 17 Objetivos de Desenvolvimento Sustentável (ODS) da UNESCO por meio da leitura, em um programa voltado para o grupo de crianças entre 5 e 15 anos em situação de exclusão social. Após a mudança da biblioteca pública para uma localização mais central, as necessidades de grupos próximos a ela se tornam evidentes e geralmente não fazem parte dos usuários regulares. Detecta-se que a grande maioria tem entre 5 e 15 anos de idade, imigrantes marroquinos de segunda geração e suas famílias apresentam deficiências em aspectos como compreensão de leitura, uso correto das facilidades da biblioteca e interação com outros usuários. Este projeto visa a quebra de barreiras por motivos de raça ou religião e destina-se a integrar os grupos acima mencionados nas atividades do diaa-dia da biblioteca, também procura estabelecer um ponto de partida para continuar nesta linha de colaboração e estabelecer as bases de um projeto com uma projeção mais ampla, tanto no tempo como no número de beneficiários.

Palavras-chave: leitura. integração socia. Biblioteca pública. Infância. Jovens. promoção da leitura. desenvolvimento sustentável. 
Beyond books: The Ricardo León Public Library and the 17 Sustainable Development Goals

Abstract: This Project, developed and executed entirely by librarians was born to work on the 17 Sustainable Development Goals of UNESCO through the books. It is a program oriented to children between 5 and 15 years old with risk of social exclusion. With the move of the Public Library to a centrical location, we noticed the needs of groups who lives nearly and aren't regular users. We noticed that the biggest part of them are Moroccan immigrants of a second generation, and their families. They show deficiencies in aspects such as reading comprehension, correct use of library services or interaction with other users of different collectives. With this project we are trying to break race or religion walls and pretend to integrate all the people previously mentioned in daily activities of the library and look for a starting point where continue with a wider projection, in the duration of the project and in the number of users reached.

Keywords: reading. social integration. Public library. childhood. teenagers. reading animation. sustainable development.

\section{Introducción}

Los orígenes de la Agenda 2030 se remontan al año 2000 cuando las Naciones Unidas dan una visión mundial sobre la lucha contra la pobreza, el hambre, las enfermedades, la falta de ingresos y de vivienda adecuada, la exclusión social, los problemas de educación y de sostenibilidad ambiental, entre otros. En ese momento surgen los ocho Objetivos de Desarrollo del Milenio (ODM), previstos para el periodo 2000-2015.

En septiembre de 2015, después de más de tres años de negociaciones e intensa participación por parte de muchas partes interesadas, los 193 estados miembros de las Naciones Unidas adoptaron la Agenda de Desarrollo post 2015 que denominaron "Transformar nuestro mundo: la Agenda 2030 para el Desarrollo Sostenible" (IFLA, 2015). El objetivo era establecer un plan para que todas las naciones se comprometieran activamente en la mejora del mundo para todos los pueblos. La nueva Agenda 2030 es un marco incluyente que plantea 17 objetivos con 169 metas de carácter integrado e indivisible y que abarcan aspectos económicos, medioambientales y sociales. En la actualidad, se habla del tema, pero no se conoce tanto porque no existe difusión precisa (MONFASANI, 2018).

La "alfabetización universal" es un término que tiene su fundamento en las campañas de alfabetización que históricamente han llevado a cabo las bibliotecas, pero que en el momento en el que la Agenda 2030 de las Naciones Unidas lo apunta en su prólogo como objetivo general universal para alcanzar en 2030, se posiciona como el aspecto más importante para trabajar desde las bibliotecas de forma local (PÉREZ-SALMERÓN, 2018).

La "función social" de la biblioteca pública sigue siendo uno de los fundamentos de su existencia. Las bibliotecas deben actualizarse permanentemente para promover la alfabetización, el aprendizaje y la lectura. Hoy el papel de la biblioteca pública es cuestionado por parte de estudiantes, investigadores y profesionales. La crítica más dura se refiere a la falta 
de implementación de un nuevo modelo de biblioteca capaz de hacer frente a las necesidades de información de los ciudadanos del siglo XXI (SUAIDEN, 2018).

En la búsqueda ese posible nuevo rol la Biblioteca Municipal Ricardo León de Galapagar desarrolló durante los meses de febrero a junio de 2018 un proyecto de animación a la lectura dirigido a un colectivo muy desfavorecido de nuestro municipio y que puede servir de ejemplo de cómo desde las bibliotecas públicas municipales se puede contribuir al marco inclusivo de los 17 objetivos del desarrollo sostenible.

\subsection{Contexto}

La Biblioteca Municipal Ricardo León de Galapagar abrió sus puertas al público en el año 1983 en el Centro Cívico Reina Sofía. Posteriormente se trasladó a la primera planta del Centro Cultural La Pocilla en 1998, lugar que ocupó hasta julio del 2015 con una superficie de apenas $247 \mathrm{~m}^{2}$.

El 4 de septiembre de 2015 se inauguró el nuevo edificio de la biblioteca, ubicada en la Plaza de la Constitución en el mismo centro de la localidad y con este cambio se ha visto incrementado de manera exponencial el número de usuarios. De 638 nuevos carnés en 2014, el último año en el Centro Cultural, a 1539 en 2015, el primer año tras el cambio al nuevo edificio. Desde entonces la cifra anual de altas en la biblioteca no ha descendido de los 1.000 carnés. La instalación moderna y luminosa cuenta con $2.000 \mathrm{~m}^{2}$ y equipamiento para responder a la creciente demanda de la localidad por lo que ahora los vecinos del municipio pueden estudiar, leer, asistir a conferencias y visitar exposiciones sin necesidad de acudir a otras bibliotecas de alrededor. El edificio posee tres plantas, más de diez espacios diferentes y acceso para discapacitados. La planta baja dispone de una amplia sala de lectura y exposiciones y un gran espacio pensado para los más pequeños (biblioteca infantil y bebeteca). La primera planta cuenta con un gran salón de actos, que en la actualidad se está mejorando con la incorporación de focos, equipo de sonido, proyector y pantalla, donde tienen cabida todos los eventos relacionados con la creación literaria y cultural. Además, hay una sala de estudios, una pequeña sala de trabajo para grupos de hasta 4 personas, una sala para realizar talleres y los diferentes clubes literarios. Finalmente, la última planta está dedicada a la sala de préstamos y consultas, la biblioteca juvenil y una sala específica de autores de Galapagar. En total, 232 puestos de lectura, además de los 42 existentes en la biblioteca infantil.

Actualmente, buscamos que la Biblioteca Ricardo León sea un lugar de encuentro único que vaya más allá del préstamo y el estudio, es decir que sea una institución social de contenido profundo y no una morada simple de acervos bibliográficos al servicio egoísta del usuario como individuo, por ende, aislada o al margen de la comunidad-pueblo-sociedad 
(MENESES, 2013). Aprovechando el contexto que nos ofrece nuestro edificio, intentamos proporcionar a los usuarios un lugar donde compartir el conocimiento y poder expresarse libremente. Además de esto, hemos querido centrar gran parte de nuestras energías en aquellos colectivos más desfavorecidos, hemos buscado - y estamos buscando- que aquellas personas con algún tipo de dificultad puedan apoyarse en nuestra labor, conocer nuestro funcionamiento desde dentro y colaborar con nosotros.

En este camino, la Biblioteca Municipal Ricardo León de Galapagar ha ganado recientemente el Premio Nacional María Moliner de Animación a la Lectura en la categoría de 20.001 a 49.999 habitantes que concede el Ministerio de Educación, Cultura y Deportes, con la colaboración de la Federación Española de Municipios y Provincias y la Fundación CocaCola. El proyecto titulado La Torre de Babel: construyendo una biblioteca para todos ha sido premiado por su labor de inclusión e integración social con mayores, desempleados y discapacitados, y el apoyo a la interculturalidad, a través de su oferta diversa de actividades de fomento de la lectura. La Comisión de Valoración del concurso reconoció el esfuerzo del municipio por hacer de la biblioteca un espacio cultural para todos, abriendo la participación ciudadana y colaboración institucional a todos los servicios y actividades de la misma.

Según datos del padrón municipal correspondientes al mes de agosto de 2017, en Galapagar la población inmigrante supera el $18 \%$, cinco puntos por encima de la media de la Comunidad de Madrid. En la localidad conviven ciudadanos de 93 países diferentes, existiendo una considerable pluralidad de lenguas y culturas. Entre las nacionalidades no españolas con mayor presencia destacan Marruecos (3,8\%) y Rumanía (3,3\%), aunque la cifra más elevada se concentra en el conjunto de los países de América Latina. La mayoría de esta población se concentra en el casco urbano alrededor de la propia biblioteca. Además, existe una importante zona de realojo de población de etnia gitana y quincalleros que vivían en asentamientos de infravivienda en el margen del río Guadarrama y que fue objeto de intervención por la Comunidad de Madrid en 2001. Este núcleo de población, en gran medida, sigue viviendo de manera apartada del resto del municipio y cuenta con una elevada tasa de analfabetismo.

Uno de los colectivos con los que menos hemos trabajado en años anteriores es el de los jóvenes de 8 a 16 años. Con el propósito de atender a este grupo de población y de reinvertir buena parte del dinero concedido por el premio recibido hemos querido focalizar nuestras energías en un nuevo proyecto de compromiso social con el municipio. Además, se da la circunstancia que Galapagar recientemente ha aparecido en los medios de comunicación 
como uno de los municipios españoles que menos gasta en políticas sociales ${ }^{1}$. Según el Estudio de la Asociación Estatal de Directoras y Gerentes en Servicios Sociales, basado en los presupuestos liquidados de los años 2015 y 2016, es el quinto municipio de la Comunidad de Madrid que menos invierte en Servicios Sociales.

\section{Objetivos}

Por todo lo anterior, en febrero de 2018 iniciamos el proyecto "Más allá de los libros" dirigido a jóvenes de 5 a 15 años en situación de exclusión social, planteando los siguientes objetivos:

- Establecer sinergias de cooperación con entidades, asociaciones y otros departamentos municipales en aras a visibilizar la utilidad de la biblioteca y su rentabilidad económica y social.

- Concienciar sobre los 17 objetivos para un desarrollo sostenible adoptados por la UNESCO.

- Dar a conocer los recursos de la biblioteca y fomentar su uso y disfrute por parte de todos los miembros de la comunidad.

- Prestar apoyo a la educación formal y al desarrollo personal y convertir la biblioteca en un elemento fundamental en materia de educación ciudadana.

- Fomentar el valor de la biblioteca como agente de cohesión social.

- Dar visibilidad a la dimensión social de la biblioteca para postularse como un servicio básico de la comunidad.

- Construir una sociedad alfabetizada, informada y participativa en el contexto actual de la globalización.

- Servir a todos los miembros de la comunidad sin discriminación alguna por origen cultural o lingüístico.

\section{Metodología}

En cada una de las sesiones del proyecto se trabajan las necesidades específicas de los participantes a través de la animación a la lectura, insistiendo en la competencia lectora, la competencia para hablar y escuchar y la competencia en composición de textos.

El Real Decreto 126/2014, de 28 de febrero², señala como primera competencia básica del currículo de la enseñanza Primaria la comunicación lingüística. El desarrollo de esta competencia se justifica y concreta en las siguientes actividades:

1) Comprensión de la realidad, comunicación oral y escrita, organización del pensamiento.

\footnotetext{
${ }^{1}$ https://es.scribd.com/document/365986644/Inversion-en-servicios-sociales-de-los-municipios-demas-de-20-000-habitantes

${ }^{2}$ BOLETÍN OFICIAL DEL ESTADO (2014). Real Decreto 126/2014, de 28 de febrero, por el que se establece el currículo básico de la Educación Primaria.
} 
2) Expresión de ideas, emociones, vivencias, opiniones, expresión oral y escrita, diálogo y relación social.

3) La conversación como medio de aprendizaje, de desarrollo personal y afectivo.

4) La construcción de relaciones iguales; el lenguaje como motor para la resolución de conflictos en la comunidad escolar.

5) La interacción verbal y no verbal adaptada a cualquier contexto.

6) La lectura y la escritura.

7) El conocimiento reflexivo de la lengua para explorar todas las estrategias expresivas que permitan una mejor interacción social.

8) El dominio y la formalización de la lengua permiten el desarrollo de la capacidad crítica y la capacidad empática para escuchar, entender y valorar las opiniones diversas transmitidas en la conversación oral y en los textos escritos.

De este modo, y con la competencia lectora como base, se pretende llegar a trabajar, al menos en una ocasión, los 17 Objetivos de Desarrollo Sostenible enunciados por la Asamblea General de Naciones Unidas para su Agenda $2030^{3}$.

Se proponen un total de 14 sesiones, de una hora de duración para los alumnos entre 5 y 10 años y de dos horas para los mayores de 10 años, distribuidas a razón de una sesión semanal. Los grupos en ningún caso superarán los quince alumnos, y dos de las sesiones se establecerán fuera de la Biblioteca, a modo de incentivo, para desarrollar una actividad diferente, una se desarrollará por entero en un el Museo Reina Sofía y otra será de carácter más lúdico, para dar como concluido el taller.

Cada sesión tendrá un desarrollo diferente -en función del contenido- pero todas ellas tendrán el trabajo sobre uno o varios cuentos como denominador común y se construirán en torno al juego y a la lectura. Así pues, los alumnos comprenderán que a través de la lectura pueden conocer todos los temas que les interesen, que hay diferentes formas de lectura y que en la Biblioteca cuentan con un espacio en que satisfacer su curiosidad, aprender y buscar apoyo en caso de que lo necesiten. La idea es conseguir crear un vínculo entre el personal bibliotecario y los participantes en el taller, que no consideren este espacio como algo hostil, sino que por el contrario encuentren en la Biblioteca un punto encuentro, o un lugar a donde dirigirse en caso de sentirse perdidos.

Para la captación de los posibles beneficiarios de esta actividad, nos dirigimos a varias asociaciones del municipio (Red de Solidaridad de Galapagar, Candelita o Cruz Roja, entre otras) y nos basamos en nuestra propia experiencia, poniendo especial atención a los potenciales beneficiarios que asistieran por su cuenta a la biblioteca (por su estratégica ubicación, en el centro mismo del pueblo, tenemos un gran número de usuarios de edades comprendidas entre los 5 y los 16 años que acuden a la biblioteca por su cuenta (ya sea por la temperatura de la misma, por la compañía, o por los servicios que se ofrecen, como la

\footnotetext{
${ }^{3} \mathrm{https}: / /$ es.unesco.org/sdgs
} 
conexión a internet). A partir de la detección de los posibles beneficiarios, el siguiente paso fue ponernos en contacto con sus familias (en varios casos con la colaboración de nuestra mediadora intercultural, que fue nuestro nexo de comunicación con las familias marroquíes) y mantener una reunión con ellos, de este modo, dejamos claras las pautas básicas del proyecto, haciendo hincapié en la absolutamente necesaria implicación de las familias.

Tras la reunión, establecimos un total de tres grupos completos:

1) Niños y niñas entre 5 y 7 años

2) Niños y niñas entre 8 y 10 años

3) Niños y niñas entre 11 y 15 años

Para el desarrollo de las sesiones, ha sido imprescindible la colaboración activa de la mediadora intercultural de origen marroquí que presta servicio en la Biblioteca Ricardo León desde el año 2016. Su presencia permite servir de enlace entre las diferentes comunidades de habla no española que residen en Galapagar, así como fomentar la toma de conciencia del valor positivo de la diversidad cultural y la promoción del diálogo intercultural. Uno de los cambios más significativos con la apertura de la nueva biblioteca ha sido el aumento considerable de la población de diferentes nacionalidades y culturas que hace uso de la misma. En la mayoría de los casos se trata de niños y jóvenes de la denominada "segunda generación" que se encuentran ante la dificultad de tener que aprender no solo la lengua del país de acogida, sino la de origen, por lo que tienen serios problemas para asimilar los contenidos académicos hasta que no alcanzan una competencia lingüística suficiente. A través de la figura del mediador intercultural se intenta desde la biblioteca potenciar la interculturalidad para desarrollar los principios de la educación en valores.

Además de contar con el trabajo de dicha mediadora, ha sido fundamental la colaboración entre la Biblioteca y organizaciones como Cruz Roja, quienes incluyen en su programa de actividades la visita a la biblioteca o sesiones específicas de animación a la lectura como las incluidas en el proyecto (siendo sesiones preparadas especialmente para ellos). Con motivo del Día Internacional de la Mujer, por ejemplo, desde Cruz Roja Juventud se incorporan a nuestras actividades un grupo de menores de su proyecto de Promoción del Éxito Escolar de niños y niñas en dificultad social.

\subsection{Finalidad}

Como se explica a lo largo de lo anteriormente expuesto, la finalidad última de este proyecto, así como de todas las actividades de estas características que desarrollamos en nuestro día a día está basada en la inclusión, la visibilidad de aquellos colectivos con dificultades o minoritarios, la integración, la cooperación, el apoyo a la educación formal y el 
hecho de convertir la biblioteca en un agente de cohesión social, siendo esta un servicio básico de la comunidad.

Además, y como parte indivisible del mismo, se busca concienciar a los beneficiarios, utilizando la lectura como herramienta principal, pero también desde el juego, con los 17 objetivos de desarrollo sostenible de la UNESCO, definidos como:

"Un llamado universal a la adopción de medidas para poner fin a la pobreza, proteger el planeta y garantizar que todas las personas gocen de paz y prosperidad.

Estos 17 Objetivos se basan en los logros de los Objetivos de Desarrollo del Milenio, aunque incluyen nuevas esferas como el cambio climático, la desigualdad económica, la innovación, el consumo sostenible y la paz y la justicia, entre otras prioridades. Los Objetivos están interrelacionados, con frecuencia la clave del éxito de uno involucrará las cuestiones más frecuentemente vinculadas con otro.

Los ODS conllevan un espíritu de colaboración y pragmatismo para elegir las mejores opciones con el fin de mejorar la vida, de manera sostenible, para las generaciones futuras. Proporcionan orientaciones y metas claras para su adopción por todos los países en conformidad con sus propias prioridades y los desafíos ambientales del mundo en general.

Los ODS son una agenda inclusiva. Abordan las causas fundamentales de la pobreza y nos unen para lograr un cambio positivo en beneficio de las personas y el planeta" 4

De este modo, y conociendo la importancia del conocimiento de cada uno de estos objetivos, y con la cantidad de opciones educativas que ofrecen, consideramos que es una interesante combinación para dirigirla a un colectivo que, no necesitando tareas de refuerzo escolar, (nos consta que reciben este tipo de apoyo por otros canales) sí que requieren mayor atención y esfuerzo.

\subsection{Desarrollo}

El desarrollo de cada sesión es diferente. Como ejemplo aportaremos el desarrollo completo de una sesión muestra de cada uno de los grupos, en las cuales se trabaja un ODS. Para las lecturas recomendadas en cada uno de los ODS trabajados ver Anexo 1.

- Grupo 1: De 5 a 7 años

- Grupo 2: De 8 a 10 años

- Grupo 3: De 11 a 15 años

\section{a. Objetivo 12: Consumo responsable y producción / Grupo 1}

Para lograr crecimiento económico y desarrollo sostenible, es urgente reducir la huella ecológica mediante un cambio en los métodos de producción y consumo de bienes y recursos. La agricultura es el principal consumidor de agua en el mundo y el riego representa hoy casi el 70 por ciento de toda el agua dulce disponible para el consumo humano.

\footnotetext{
${ }^{4}$ http://www.undp.org/content/undp/es/home/sustainable-development-goals.html
} 
La gestión eficiente de los recursos naturales compartidos y la forma en que se eliminan los desechos tóxicos y los contaminantes son vitales para lograr este objetivo. También es importante instar a las industrias, los negocios y los consumidores a reciclar y reducir los desechos, como asimismo apoyar a los países en desarrollo a avanzar hacia patrones sostenibles de consumo para 2030. En este contexto, es importante reducir a la mitad el desperdicio per cápita de alimentos en el mundo a nivel de comercio minorista y consumidores para crear cadenas de producción y suministro más eficientes. Esto puede aportar a la seguridad alimentaria y llevarnos hacia una economía que utilice los recursos de manera más eficiente. ${ }^{5}$

- Duración de la sesión: 60 minutos

- Asistentes: 9

\section{Primera parte (5 $\mathrm{min}$.$) : Sellamos el pasaporte lector (Ver anexo 2)$}

Actividad sencilla que ayuda a que los participantes se concentren, vayan entrando en la dinámica de la sesión y sirve para dar tiempo a que los rezagados se incorporen. Además, ayuda a construir una rutina y a llevar un control sobre la asistencia a las sesiones.

\section{Segunda parte (10 min.): Refrescamos la memoria}

Al haber un intervalo largo entre sesiones, consideramos interesante re-afianzar conocimientos trabajados en la sesión anterior, de este modo observamos si los conceptos han sido correctamente comprendidos, si algo no ha quedado claro y si hay que retomar alguna idea.

\section{Tercera parte (30 min.): Lectura}

En esta ocasión escogemos Plantando los árboles de Kenia, de Claire A. Nívola. Un álbum ilustrado que narra la historia de la Premio Nobel de la Paz 2004 Wangari Maathai, fundadora del movimiento Cinturón Verde. La protagonista, un gran ejemplo de esfuerzo y superación, regresa de sus estudios en Estados Unidos y encuentra que Kenia está completamente deforestada, la fauna esquilmada y la perspectiva de futuro es descorazonadora. Con su esfuerzo y ayuda del resto de mujeres de su país, pone en marcha un movimiento que ayudará a repoblar de árboles Kenia, y contribuir a convertirla en el país que ella había conocido. Desde una perspectiva sencilla, con una prosa lírica clara y comprensible para los más pequeños, acompañada de bellas ilustraciones, acercamos el concepto de deforestación, de consumo abusivo de los recursos y transversalmente -como procuramos hacer en nuestras actividades diarias, tanto dentro como fuera de este proyecto- trabajamos la

\footnotetext{
${ }^{5} \mathrm{http} / / /$ www.undp.org/content/undp/es/home/sustainable-development-goals/goal-12-responsibleconsumption-and-production.html
} 
perspectiva de género, necesaria siempre, pero aún más cuando nos dirigimos al colectivo que nos ocupa, tratado de forma más extensa en apartados anteriores.

Concluido el libro y como en cada sesión, comentamos aspectos generales de la lectura tales como:

- Resumen de la historia

- Personaje protagonista

- ¿Qué hubierais hecho de estar en su lugar?

- Comentarios y preguntas

\section{Cuarta parte (15 min.): Juego}

En esta ocasión utilizamos "El bingo del residuo", un sencillo y divertido juego que funciona como el bingo tradicional, pero en lugar de con números con residuos. Al cantar línea o bingo, el ganador o ganadora tiene que acertar en qué contenedor o de qué manera tenemos que desechar cada uno de los restos. Ver Anexo 3.

\section{b. Objetivo 5: Igualdad de género / Grupo 2}

Poner fin a todas las formas de discriminación contra las mujeres y niñas no es solo un derecho humano básico, sino que además es crucial para acelerar el desarrollo sostenible. Ha sido demostrado una y otra vez que empoderar a las mujeres y niñas tiene un efecto multiplicador y ayuda a promover el crecimiento económico y el desarrollo a nivel mundial.

Desde 2000, la igualdad de género es un aspecto primordial de la labor del PNUD, sus aliados de la ONU y el resto de la comunidad global, y se han registrado algunos avances extraordinarios. Más niñas asisten hoy a la escuela que hace 15 años y en la mayoría de las regiones se logró la paridad de género en educación primaria. Además, las mujeres constituyen hoy el 41 por ciento de la fuerza laboral remunerada no agrícola, en comparación con el 35 por ciento en 1990.

Los Objetivos de Desarrollo Sostenible se apoyarán en estos logros para garantizar el fin de la discriminación a mujeres y niñas en todo el mundo. Sin embargo, en algunas regiones aún existen grandes desigualdades en el mercado del trabajo, donde a algunas mujeres se les ha negado sistemáticamente el acceso igualitario al empleo. Los obstáculos más difíciles de superar y que aún persisten son la violencia y la explotación sexual, la división desigual del trabajo no remunerado -tanto doméstico como en el cuidado de otras personas- y la discriminación en la toma de decisiones en el ámbito público.

Garantizar el acceso universal a salud reproductiva y sexual y otorgar a la mujer derechos igualitarios en el acceso a recursos económicos, como tierras y propiedades, son metas fundamentales para conseguir este objetivo. Hoy más mujeres que nunca ocupan cargos 
públicos, pero alentar a más mujeres para que se conviertan en líderes en todas las regiones ayudará a fortalecer las políticas y las leyes orientadas a lograr una mayor igualdad entre los géneros. ${ }^{6}$

- Duración de la sesión: 60 minutos

- Asistentes: 8

Primera parte (5 min.): Sellamos el pasaporte lector Ver 5.1

Segunda parte (10 min.): Refrescamos la memoria Ver 5.2

Tercera parte (30 min.): Lectura

Escogemos uno de los bestsellers del año: Cuentos de buenas noches para niñas rebeldes, de Elena Favilli. Pese a haber sido uno de los regalos estrella en las Navidades de 2017 y estar presente en gran parte de aulas y bibliotecas escolares, únicamente una alumna lo conocía. Quizá su éxito resida en sus variadas ilustraciones, en la brevedad de sus historias o en la sencillez que están escritas. Sea como fuere, escogemos al azar tantas historias como asistentes, reservándonos para el final la lectura de la breve historia de Manal Al Sharif, por su importancia a la hora de desarrollar la cuarta parte de la actividad, como veremos más adelante.

\section{Cuarta parte (10 min.): La historia de Manal Al Sharif}

Escogemos esta lectura por varios motivos, algunos de los principales son, el hecho de que es un suceso ocurrido hace relativamente poco tiempo (2011), difundido en plataformas conocidas para los menores con los que trabajamos (YouTube, por ejemplo) y tal vez de esta manera podría ser más cercano para los participantes.

Manal al Sharif conducía un coche en compañía de su hermano, Muhammad al Sharif, cuando unos agentes de tráfico les dieron el alto. Inmediatamente les detuvieron, aunque a las pocas horas fueron liberados tras hacerles firmar unas declaraciones en las que se comprometían a que Manal al Sharif no volvería a conducir en Arabia Saudí.

En la madrugada del día siguiente los dos fueron detenidos de nuevo e interrogados: Muhammad quedó libre, pero Manal fue trasladada a una prisión de mujeres de Dammanm.

Manal participaba en la campaña "Women 2 Drive" (Mujeres al volante) contra la prohibición de que las mujeres conduzcan en Arabia Saudí. Se trata de una campaña pacífica en la cual las mujeres se graban conduciendo y hacen públicas en la web las imágenes. Manal había subido a YouTube un vídeo de este tipo.

\footnotetext{
${ }^{6} \mathrm{http} / / /$ www.undp.org/content/undp/es/home/sustainable-development-goals/goal-5-genderequality.html
} 
Las mujeres de Arabia Saudí se enfrentan a una severa discriminación tanto en la ley como en la práctica. Deben obtener el permiso de un tutor varón para poder viajar, realizar un trabajo remunerado, cursar estudios superiores o casarse. La violencia de género es, según se cree, generalizada. ${ }^{7}$

Tras la lectura de la historia, proyectamos el vídeo ${ }^{8}$ al que se hace referencia, en árabe, con subtítulos en inglés. Parte de los participantes entienden árabe y se lo explican a sus compañeros. A continuación, hacemos un breve debate sobre igualdad de género, sus perspectivas, sus ideas, casos que conocen...

\section{Quinta parte (10 min.): Creamos nuestra propia página de la historia}

Al modo de la composición en Cuentos de buenas noches para niñas rebeldes, cada participante tiene que retratar a mujer (inventada) y escribir brevemente su historia. Ver Anexo 4 para un ejemplo.

\section{c. Objetivo 1: Fin de la pobreza y Objetivo 2: Hambre cero / Grupo 3}

En este caso, y dado que contamos con menos sesiones que objetivos a trabajar, y teniendo en cuenta que hay algunos que pueden trabajarse de manera simultánea, consideramos interesante trabajar el primer objetivo y el segundo al mismo tiempo, dando como resultado una sesión interactiva y ampliable en un futuro.

El hambre extrema y la desnutrición siguen siendo grandes obstáculos para el desarrollo de muchos países. Se estima que 795 millones de personas sufrían de desnutrición crónica en 2014, a menudo como consecuencia directa de la degradación ambiental, la sequía y la pérdida de biodiversidad. Más de 90 millones de niños menores de cinco años tienen un peso peligrosamente bajo y una de cada cuatro personas pasa hambre en África.

Los Objetivos de Desarrollo Sostenible buscan terminar con todas las formas de hambre y desnutrición para 2030 y velar por el acceso de todas las personas, en especial los niños, a una alimentación suficiente y nutritiva durante todo el año. Esta tarea implica promover prácticas agrícolas sostenibles a través del apoyo a los pequeños agricultores y el acceso igualitario a la tierra, la tecnología y los mercados ${ }^{9}$.

- Duración de la sesión: 120 minutos

- Asistentes: 9

Primera parte (5 min.): Sellamos el pasaporte lector Ver 5.1

\footnotetext{
${ }^{7}$ https://www.es.amnesty.org/actua/acciones/arabia-saudi-manal-al-sharif/

${ }^{8} \mathrm{https}: / /$ www.youtube.com/watch?v=sowNSH_W2rO

${ }^{9} \mathrm{http} / / / \mathrm{www}$. undp.org/content/undp/es/home/sustainable-development-goals/goal-2-zerohunger.html
} 
Segunda parte (10 min.): Refrescamos la memoria Ver 5.2

Tercera parte: Oliver Twist / La pobreza (60 min.)

En esta ocasión escogemos los medios audiovisuales para acercar la temática a los participantes, a través de las adaptaciones cinematográficas de Oliver Twist y con el visionado de algunos vídeos de la misma temática.

- Secuencia de Oliver Twist

- https://www.youtube.com/watch?v=GKxGsWikHkE

- Pregunta: ¿Qué sienten los niños que aparecen en el video?

- Objetivo: identificar el hambre

- Secuencia de Oliver Twist

○ https://www.youtube.com/watch?v=w-7xEoCtEfk

○ Objetivo: Identificar la pobreza, el dolor y sufrimiento

- Tráiler de Oliver Twist

○ https://www.youtube.com/watch?v=aXtL3IbM3Zs

- Resumen de Oliver Twist e introducción de Dickens:

○ https://www.youtube.com/watch?v=JtcQD_FKm4s

- Debate sobre si estos hechos pasan hoy en día y sobre la pobreza extrema

- Videos sobre pobreza:

- La situación de pobreza, por ONG Educo:

- https://www.youtube.com/watch?v=B3Jjq-e-cYo

- La pobreza en el mundo, por Manos Unidas:

- https://www.youtube.com/watch?v=nIdXZIJvXRM

- El hambre en el mundo, por Manos Unidas:

- https://www.youtube.com/watch?v=owaMKKJs-y8

○ La pobreza extrema:

- https://www.youtube.com/watch?v=_48084MuFag

Cuarta parte: Juego de simulación sobre las necesidades básicas (45 min.)

Adaptación de la propuesta de Mary Gale Smith ${ }^{10}$

\section{RESULTADOS}

Uno de los resultados más satisfactorios tras concluir el proyecto por desgracia no es cuantificable. Se trata de poder observar el grado de cohesión, complicidad y disfrute que han ido generando los participantes entre ellos, así como con los dinamizadores de las sesiones

${ }^{10} \mathrm{https}: / /$ greenteacher.com/article\%20files/necesidadesbasicas.pdf 
(parte del personal de la Biblioteca), del mismo modo que su interés por la lectura y comodidad en un entorno como la biblioteca, hostil antes para muchos de ellos. Esto, junto con los buenos comentarios de las familias y el interés de todos ellos en formar parte de este proyecto en años venideros, es uno de los mejores resultados a tener en cuenta de cara a proseguir con esta iniciativa e incluso derivarla a otros entornos, asociaciones o colectivos (Para una explicación más detallada ir al punto 8).

No obstante, hemos valorado otros criterios para poder demostrar los resultados de este proyecto. Se propone un ejercicio inicial, de una duración máxima de 20 minutos, que podría completarse fácilmente en diez. En este ejercicio se pretende determinar el punto de partida, así como el nivel inicial y tener un resultado para comparar una vez finalizado el proyecto. De este modo, los resultados fueron los que se muestran a continuación:

Figura 1. Evaluación inicial de los participantes (Grupo 1)

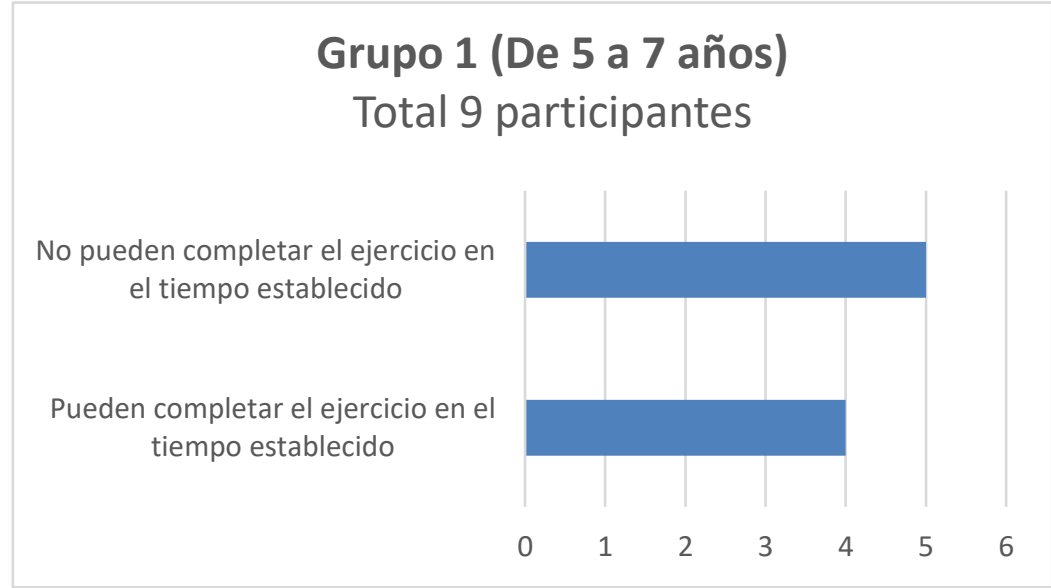

Figura 2. Evaluación inicial de los participantes (Grupo 2)

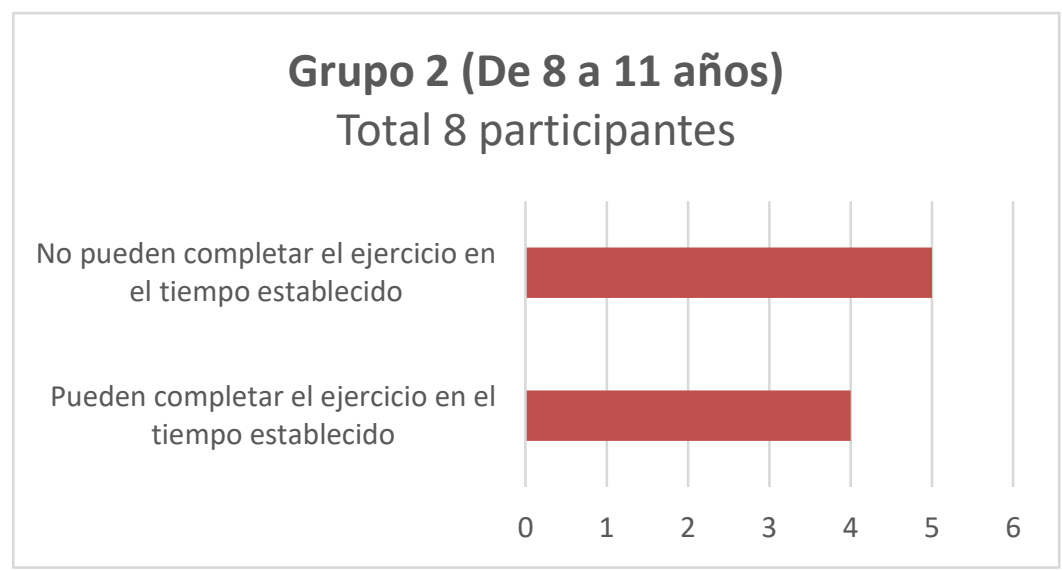


Figura 3. Evaluación inicial de los participantes (Grupo 3)

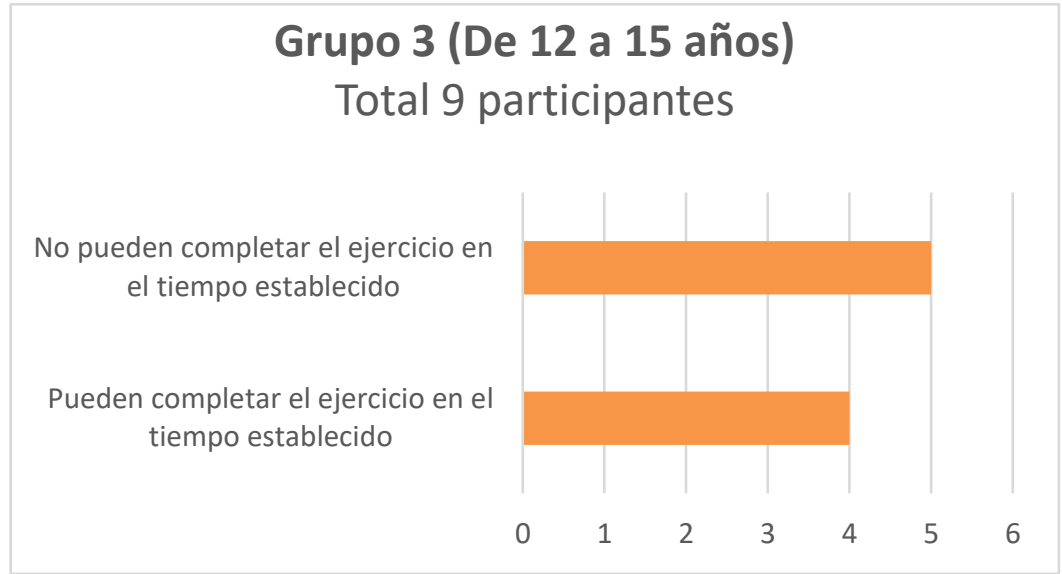

Detectamos que la mayor dificultad a la hora de terminar el ejercicio no es la falta de capacidad (de hecho, más adelante algunos de los participantes demostraron tener capacidades por encima de la media en determinadas áreas) si no la ausencia de límites y sobre todo la falta de hábito lector, dificultad en la comprensión lectora y falta de atención generalizada, así como el hecho de encontrarse -muchos de ellos- en un entorno nuevo y distinto de los que suelen frecuentar.

Más allá de conseguir terminar o no el ejercicio, observamos que predominan las respuestas incorrectas por la ausencia de comprensión lectora a la hora de leer los enunciados. Como muestra, a continuación, incluimos un gráfico con la cantidad de respuestas correctas, incorrectas y sin contestar, correspondiente a los grupos 1 y 2 :

Figura 4. Nivel de comprensión lectora inicial de los participantes

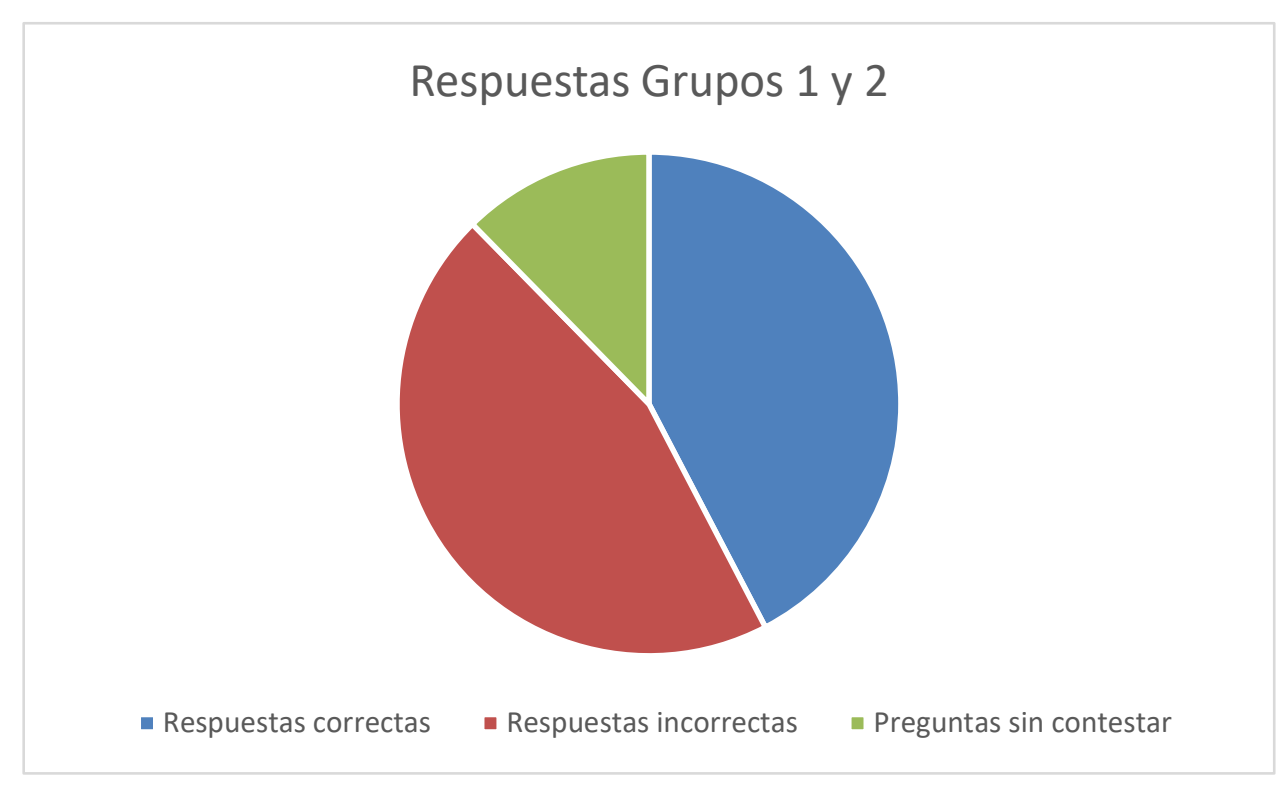


Una vez completadas todas las sesiones, proponemos un ejercicio semejante y del mismo nivel que el inicial y con el mismo tiempo de resolución (20 minutos), observamos que la totalidad de los participantes pueden terminarlo en tiempo, e incluso hacer varios ejercicios en el tiempo correspondiente.

Los resultados quedaron de la siguiente manera:

Figura 5. Evaluación final de los participantes

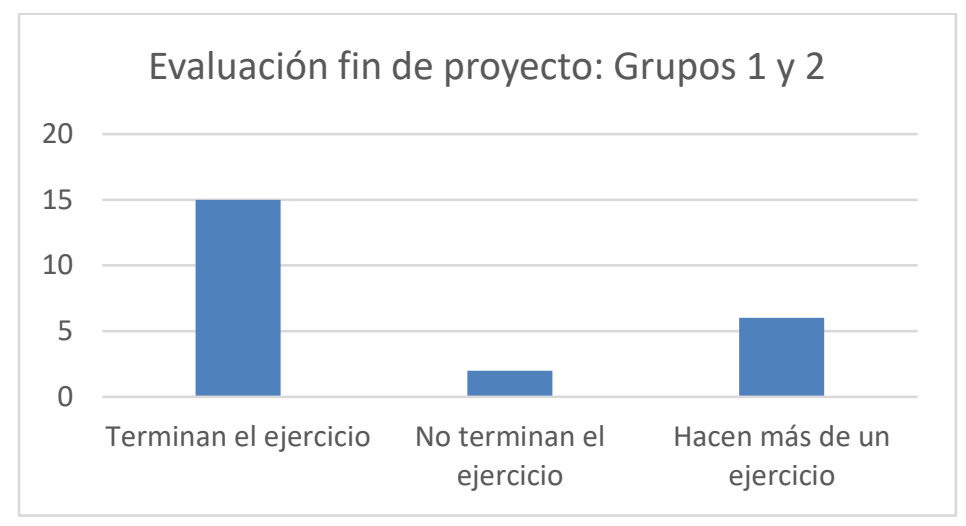

Además, observamos que el número de respuestas correctas se ve incrementado sustancialmente, así como se ven disminuidas las faltas de ortografía (no así eliminadas por completo), de este modo las respuestas quedarían de la siguiente manera:

Figura 6. Nivel de comprensión lectora final de los participantes

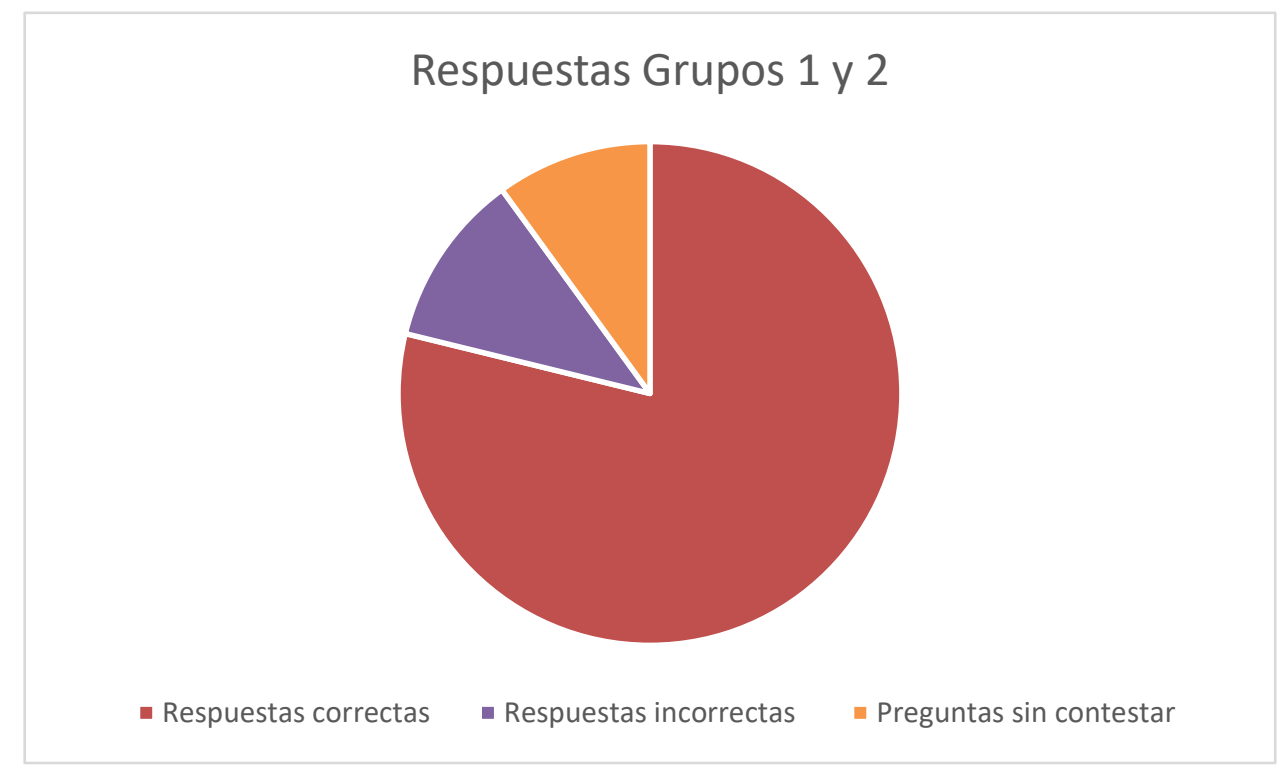




\section{CRITERIOS}

Los criterios evaluables de este proyecto se definen en las fichas de competencias lectoras que empleamos para cada uno de los grupos, compuestas siempre por una lectura y varios ejercicios adaptados a la necesidad y el nivel de los participantes. En todo caso, se procura que haya varios modelos. Algunos de los modelos utilizados pueden consultarse en el Anexo 5.

Los procedimientos de evaluación quedan reflejados en el punto anterior. De todas formas, es oportuno aclarar que en ningún caso se ha pretendido hacer un análisis único de competencias lectoras, sino que los resultados son favorables tanto si tenemos en cuenta los aspectos objetivos como si empleamos los subjetivos, de manera que se tras el taller se detectan los siguientes resultados:

Datos cuantificables:

- Mejora sustancial de las calificaciones.

- Asistencia de los participantes a más de un $80 \%$ de las sesiones.

- Aumento de la velocidad y capacidad de lectoescritura.

Datos no cuantificables:

- Satisfacción de los participantes.

- Interés y colaboración de las familias.

- Interés por parte de otros usuarios de la biblioteca en participar en proyectos semejantes.

- Interés por parte de asociaciones, tales como Cruz Roja, que se encargó de impartir las sesiones relativas al Objetivo 3: Salud y Bienestar a todos los niveles, además de ofrecer actividades alternativas, tales como una sesión de prevención de accidentes para familias o la disposición de mesas informativas sobre reciclaje y de prevención de accidentes relativos a las altas temperaturas.

\section{RECOMPENSAS}

Como se ha mencionado anteriormente, se proponen varias actividades diferentes en las que trabajar los ODS, fuera de los muros de la biblioteca y de un modo lúdico y a modo de incentivo, por la buena predisposición en las sesiones.

Las recompensas están financiadas íntegramente y como se ha mencionado antes, por la cantidad recibida como dotación económica del Premio Nacional María Moliner concedido en 2017 a la Biblioteca Ricardo León y fueron las siguientes:

\section{- Visita / Taller al Museo Nacional Centro de Arte Reina Sofía (Grupos 1 y 2)}

Con la idea de promover la educación de calidad (Objetivo 4) se propone esta estimulante visita para los grupos de los más pequeños. Fotos en Anexo 6.

\section{- Trabajamos con las manos: Alexander Calder}

Con los más mayores trabajamos la figura de Alexander Calder, importante escultor estadounidense. Desconocido para la totalidad de los participantes, la sesión consistió en leer 
parte de su biografía y hacer una reproducción a escala de uno de sus famosos móviles. Fotos en Anexo 7.

\section{- Recompensa final: Visita con familias al Safari Park de Madrid}

Con la idea de trabajar uno de los ODS más atractivos de cara a los menores, proponemos como colofón para el proyecto una visita de día completo al Safari Park. Allí, de la mano de una guía, trabajamos directamente el Objetivo 15: Vida de ecosistemas terrestres. En esta actividad quisimos implicar a las familias, ya que cada asistente tenía que venir acompañado de un familiar, pero también a los beneficiarios del Promoción del Éxito Escolar de niños y niñas en dificultad social de Cruz Roja Juventud, con quienes hemos trabajado en diversas ocasiones desde la Biblioteca. Foto en el Anexo 8.

\section{COLABORACIÓN CON OTRAS ENTIDADES EN EL DÍA A DÍA DE LA BIBLIOTECA}

Pese a que son iniciativas que se trabajan al margen del proyecto que nos ocupa, hemos considerado interesante hacer referencia a algunas de las colaboraciones más satisfactorias que hemos emprendido, de cara a dar una visión más global del día a día de la Biblioteca:

Además de la principal sinergia establecida con Cruz Roja y anteriormente descrita, habitualmente la biblioteca Ricardo León colabora con diversas asociaciones entre las que se encuentran:

La Red de Solidaridad de Galapagar: Pese a haber hecho colaboraciones esporádicas, desde el mes de enero de 2017 iniciamos una nueva colaboración para trabajar con familias en riesgo de exclusión social a través de diferentes actividades de animación a la lectura. Esta red nace ante las carencias que muchas familias de este y otros municipios padecen (en la actualidad existen en nuestra localidad 127 familias que perciben la Renta Mínima de Inserción), en aspectos tan importantes como la educación, la alimentación, el empleo, la vivienda, la soledad, etc.... Con ellos hemos puesto en marcha actividades tales como el Maratón de Cuentos, abierto a todo el público y al que acudieron más de 300 participantes. Ver fotos en Anexo 9

Casa familiar San Francisco de Asís de Torrelodones: A razón de una sesión al mes, los residentes de dicha institución se desplazan a nuestro municipio para ser partícipes de nuestras acciones. En este caso las sesiones se preparan de una forma diferente, atendiendo de forma individualizada de las necesidades de los participantes, ya que se trata de personas en situación de discapacidad intelectual y enfermedad mental. Fomentando el desplazamiento de la biblioteca fuera del edificio, también hemos proyectado actividades en sus dependencias, 
como puede verse en las fotografías del Anexo 10, algo valorado de forma muy positiva entre los residentes, que -en palabras de la responsable de la Casa Familiar- "se sienten estimulados intelectualmente y reciben la visita de la biblioteca como una fiesta".

Acervo intergeneracional: La Biblioteca Municipal Ricardo León cuenta con varios programas dirigidos a personas de avanzada edad. Desde un taller de lectura fácil semanal hasta un proyecto con voluntarios, titulado "El Agente Prestatario una biblioteca para todas las edades" que acerca la lectura a las personas que no pueden desplazarse a la biblioteca. Se trata de una iniciativa que considera a la biblioteca pública municipal y su área de influencia y de cohesión social como espacio de aprendizaje y servicio para los ciudadanos y que pretende unir diferentes generaciones para desarrollar nuevas relaciones entre personas y posibilitar el desarrollo de una nueva reciprocidad intergeneracional que esté vinculada al diálogo y a la conexión entre generaciones.

A través de este programa, personas voluntarias (agentes prestatarios) se convierten en compañeras de lectura de personas con algún tipo de problemas de movilidad o minusvalía, poniendo a su alcance todos los documentos en diferentes soportes, servicios y productos culturales de las bibliotecas públicas municipales y favoreciendo la cohesión. Las parejas lectoras se reúnen de forma periódica en el domicilio del beneficiario en sesiones informales, para desarrollar actividades centradas en intereses comunes que incluyen la lectura, juegos, aficiones y el préstamo bibliotecario y estableciendo en última instancia una estrecha relación de amistad donde el respeto y la solidaridad están presentes. Foto en Anexo 11.

\section{CONCLUSIONES}

Tras los buenos resultados obtenidos con la ejecución de este proyecto y observando los beneficios del mismo en los usuarios de la biblioteca, se propone continuar con la misma idea de cara a los participantes que se han quedado en lista de espera en esta primera tentativa. Se valorará la idea de continuar con sesiones diferentes de cara a aquellos que este año han manifestado su interés en continuar en cursos sucesivos.

Pero quizá una de las colaboraciones de más importancia en este ámbito es la que se establece con Cruz Roja Juventud: la de preparar una réplica del proyecto y llevarla a los centros educativos del municipio, de este modo se podrán trabajar los 17 ODS a través de la lectura y llevar la biblioteca a otros lugares, en este caso colegios e institutos, pero considerando la posibilidad de acercar el proyecto a otro tipo de asociaciones y a otro tipo de colectivos. 
Consideramos que este proyecto es lo suficientemente versátil y sencillo en su aplicación como para poder moverlo por todo tipo de centros y a todo tipo de colectivos. Con la ayuda de Cruz Roja Juventud, sus voluntarios y profesionales, perseguimos la idea de ponerlo en práctica a un nivel superior confluyendo siempre en la lectura y en el conocimiento de los ODS.

Así pues, nace la idea de crear un Libro Viajero compuesto por las diferentes clases donde se ponga en práctica el proyecto, en el que se mencionen lecturas relativas a los ODS y que una vez terminado forme parte de la colección de la Biblioteca, para poder acercarlo de forma fácil a los usuarios e incluso tenerlo en exposición durante el periodo de tiempo que se considere necesario.

Por último, la experiencia desarrollada nos reafirma en la idea de que las bibliotecas públicas municipales deben constituirse como espacios propicios para la implementación de la Agenda 2030 y contribuyen a mejorar la igualdad de oportunidades de las personas más vulnerables de la sociedad.

\section{REFERENCIAS BIBLIOGRÁFICAS}

INTERNATIONAL FEDERATION OF LIBRARY ASSOCIATIONS AND INSTITUTIONS (IFLA). Las bibliotecas y la implementación de la Agenda 2030 de la ONU. International Federation of Library Associations and Institutions. Programa de Acción para el Desarrollo a través de las Bibliotecas (IFLA/ALP). 2015.2 Accesible en: http://www.fesabid.org/sites/default/files/repositorio/2015 bibliotecasyagenda2030.pdf

MENESES TELLO, Felipe. Bibliotecas y sociedad: el paradigma social de la biblioteca pública. Investigación bibliotecológica, v. 27, n. 61, p. 157-173, 2013.

MONFANASI, Rosa. La situación de la bibliotecología argentina en la aplicación de los Objetivos de Desarrollo Sostenible (ODS) de la Agenda 2030. Revista Prefacio, v. 2, n. 2, pp. 7-21, 2018.

PÉREZ-SALMERÓN, Gloria. Mapa de ideas para la transformación de la estrategia de la IFLA. Anuario ThinkEPI, v. 12, p. 48-55, 2018.

SUAIDEN, Emir-José. La biblioteca pública y las competencias del siglo XXI". El profesional de la información, v. 27, n. 5, pp. 1136-1144, 2018. 


\section{ANEXOS}

\section{Anexo 1: Lecturas recomendadas para el trabajdo de los 17 ODS}

\section{Objetivo 1: Fin de la pobreza}

- Charles Douglas Lummis: Si el mundo fuera una aldea de cien personas (El Aleph, 2008)

- José Luis Olaizola: Cucho (SM, 2002) (En este caso es recomendable trabajar la historia en varias sesiones, siempre con niños y niñas a partir de 10 años)

\section{Objetivo 2: Hambre cero}

- Claudia Rueda: iVaya apetito tiene el zorrito! (RBA, 2007)

- Antonio Gramsci/Laia Domènech: El ratón y la montaña (Milrazones, 2017)

\section{Objetivo 3: Salud y bienestar}

- David Aceituno/Daniel Montero: La rebelión de las verduras (BEASCOA, 2016)

- Valentín Fuster: Monstruos supersanos (Planeta, 2010)

- Anton Fortes: A la sombra de los anacardos (OQO Editoras, 2010)

\section{Objetivo 4: Educación de calidad}

- Raphaelle Frier: Malala: Por el derecho de las niñas a la educación (Blume, 2016)

- Jeanette Winter: Malala/Ikbal una niña/o valiente de Pakistan (Juventud, 2015)

\section{Objetivo 5: Igualdad de género}

- Adela Turín: Rosa caramelo (Kalandraka, 2012)

- Elena Favilli: Cuentos de buenas noches para niñas rebeldes (Planeta, 2017)

- Helena Berenguer/Carmen Ivars: La peluca de Luca (2013)

\section{Objetivo 6: Agua limpia y saneamiento}

- Jen Green y Mike Gordon: ¿Por qué debo ahorrar agua? (Anaya, 2012)

- Pep Bruno: Pétala (OQO, 2008)

\section{Objetivo 7: Energía asequible y no contaminante}

- Jen Green y Mike Gordon: ¿Por qué debo ahorrar energía? (Anaya, 2012)

- Melanie Walsh: 10 cosas que puedo hacer para ayudar a mi mundo (RBA)

\section{Objetivo 8: Trabajo decente y crecimiento económico}

- Junyent y Serrano: Mon y Nedita: mi primer libro de economía (Combel, 2017)

- H.A. Rey: Jorge el curioso: El puesto de limonada (2016) 
Objetivo 9: Industria, innovación e infraestructura

- Roald Dahl: Charlie y la fábrica de chocolate (1964)

\section{Objetivo 10: Reducción de las desigualdades}

- Élisa Gëhin: Érase otra vez un bosque (Ed. Oxfam Intermon)

- Isabelle Carrier: El cazo de Lorenzo (Juventud, 2010)

- Jairo Buitrago/Rafael Yockteng: Eloísa y los bichos (El Jinete Azul, 2012)

\section{Objetivo 11: Ciudades y comunidades sostenibles}

- Jorg Müller: El soldadito de plomo (Lóguez, 2005)

- Mike Curato: El pequeño Elliot en la gran ciudad (B de Block, 2015)

- Ingela P. Arrhenius: La ciudad (Coco Books, 2017)

\section{Objetivo 12: Producción y consumo responsables}

- Claire A. Nivola: Plantando los árboles de Kenia (Juventud, 2012)

- Donald Grant: Nuestro planeta en peligro (Juventud, 2008)

\section{Objetivo 13: Acción por el clima}

- Robert E. Wells: Oso polar ¿̇sabes por qué se deshiela tu mundo? (Juventud, 2009)

- Satoe Tone: El viaje de los pingüinos (SM, 2015)

\section{Objetivo 14: Vida submarina}

- Rocío Martínez: La historia del "Rainbow Warrior" (Kalandraka, 2008)

- Roberto Aliaga: ¿Te cuento un secreto? Cuando me convertí en sirena (Anaya, 2016)

\section{Objetivo 15: Vida de ecosistemas terrestres}

- Patrick George: Rescate animal (Juventud, 2016)

- Indira G. Bush Tapla: Shamsung, la pequeña mofeta (Universo de letras, 2018)

\section{Objetivo 16: Paz, justicia e instituciones sólidas}

- Éric Battut: Los niños no quieren la guerra (Juventud, 2001)

- David McKee: Negros y blancos (Anaya, 2008)

- Amavisca/Guridi: Sin agua y sin pan (Nubeocho, 2016)

\section{Objetivo 17: Alianzas para lograr los objetivos}

Para trabajar este objetivo y debido a la especificidad del mismo, proponemos algunas lecturas relacionadas con la colaboración y la importancia del trabajo en equipo, consideramos que este es un buen punto de partida desde el que poder trabajar este último objetivo:

- Anna Aparicio: Agua (Babulinka Books, 2016)

- Miguel Cerro: Después de la lluvia (Kalandraka, 2015)

- Leo Lionni: Nadarín (Kalandraka, 2017) 
Anexo 2: Muestra de trabajo en la sesión relativa a la Igualdad de género

Kelly era una muy valiente, cuando no dejaban guerrera

hacer nada a las chicas pero ella no hico casa

estudió y consigivió carrera, hasta que un día. la pillaran.

la hicieron jurar que dejaria de hacer eso y be

quedaria en casa limpiando y cocinando, ella

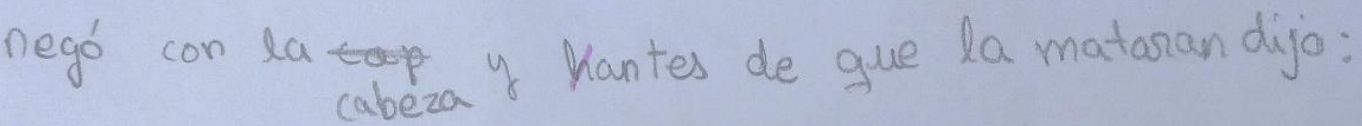

- Cla que haga esto espalientey la que no lo

haga es 1 Cobarde 


\section{Anexo 3: Modelos de fichas de evaluación de competencias lectoras ${ }^{11}$}

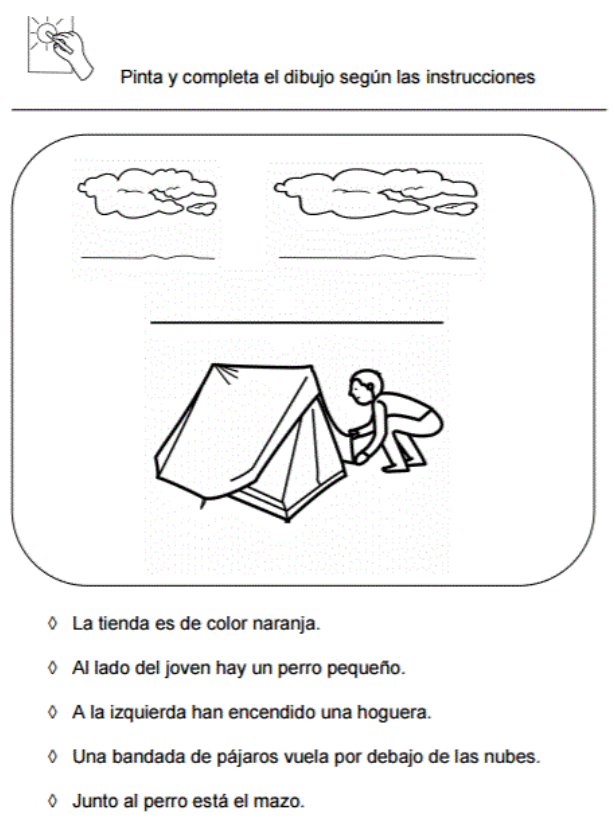

Cuando tenia 4 años, nacieron mis hermanos Fernando y Javier, san gemelos. Al principia, estaba un poca celosa, pero se me pasó al ver que dejaban de llorar cuando yo me ponia a bailar.

Contesta:

¿Coma se titula la lectura?

¿Cuantos hermanos tiene Maria?

¿Coma se llaman los hermanos de Maria?

¿Qué quiere decir que san hermanos gemelos?

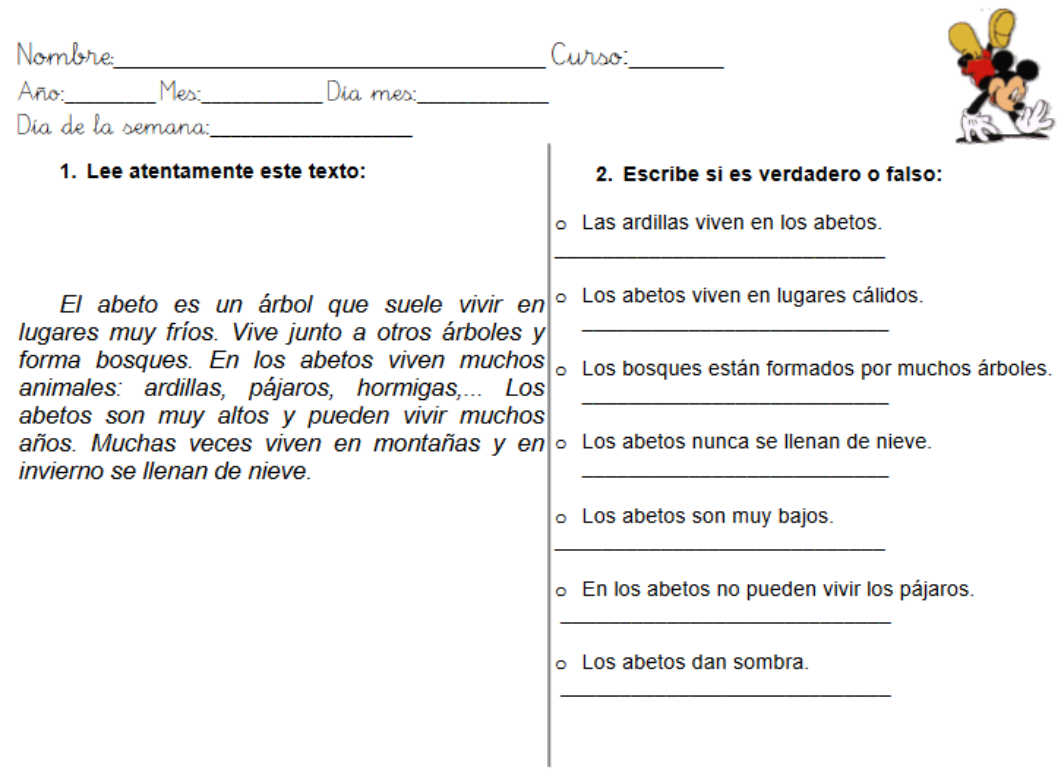

L2-2

${ }^{11}$ https://www.aulapt.org/2015/05/28/mas-de-200-fichas-de-comprension-de-textos-cortos-para-10-y2o/ 
Anexo 4: Fotos Visita/Taller Museo Nacional Centro de Arte Reina Sofía
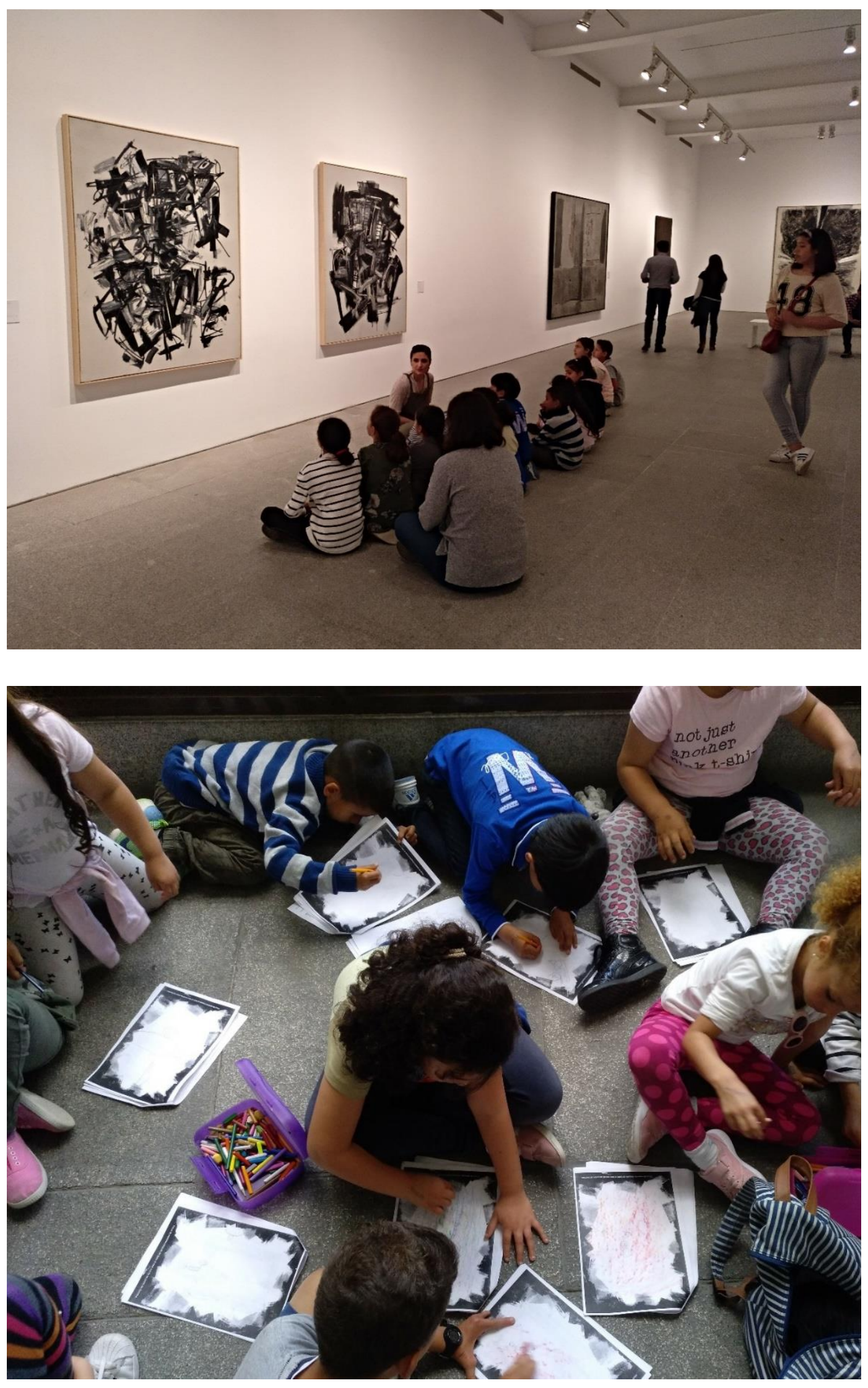
Anexo 5: Fotos del taller Trabajamos con las manos: Alexander Calder

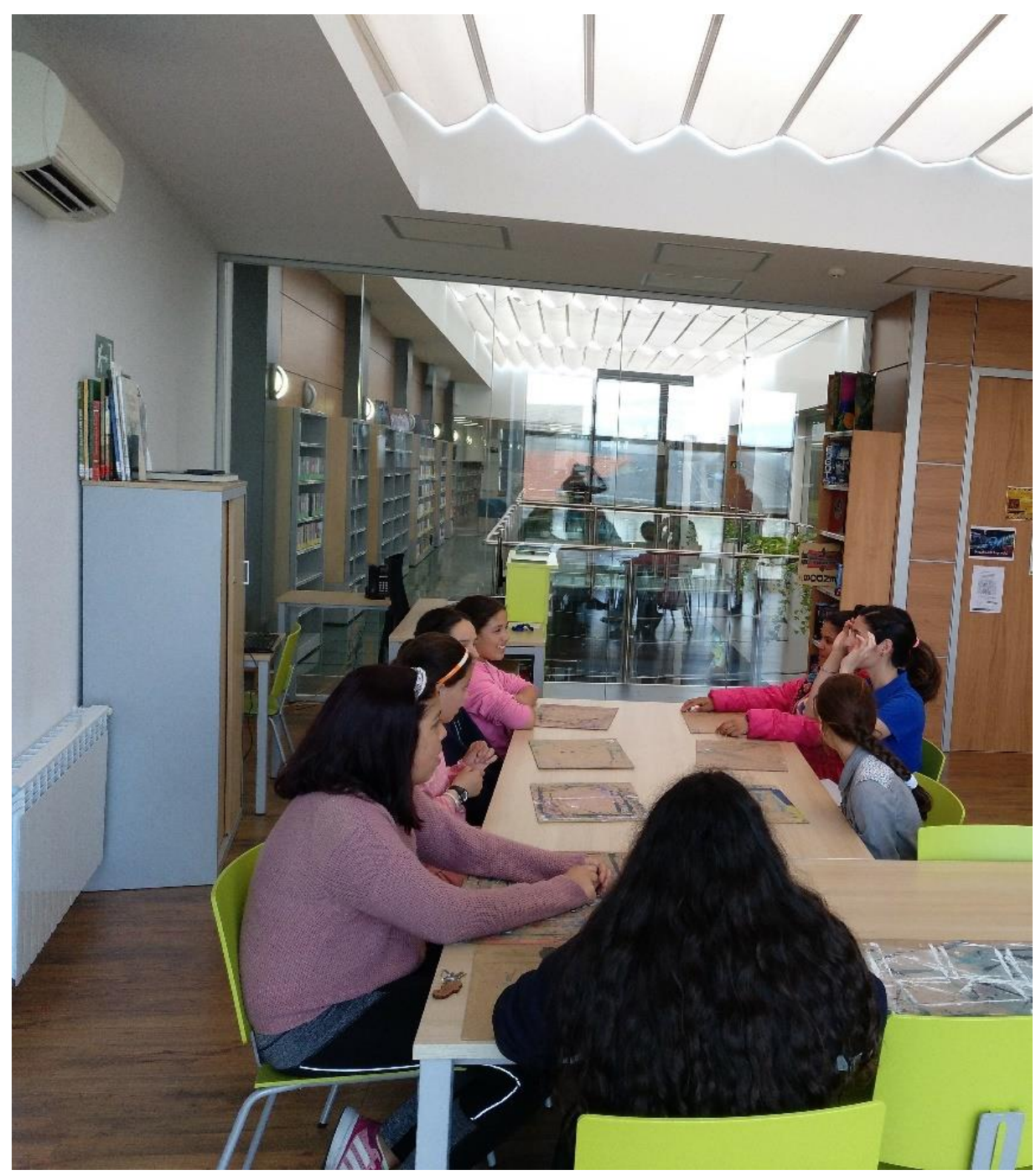


Anexo 6: La recompensa final: Visita al Safari Park

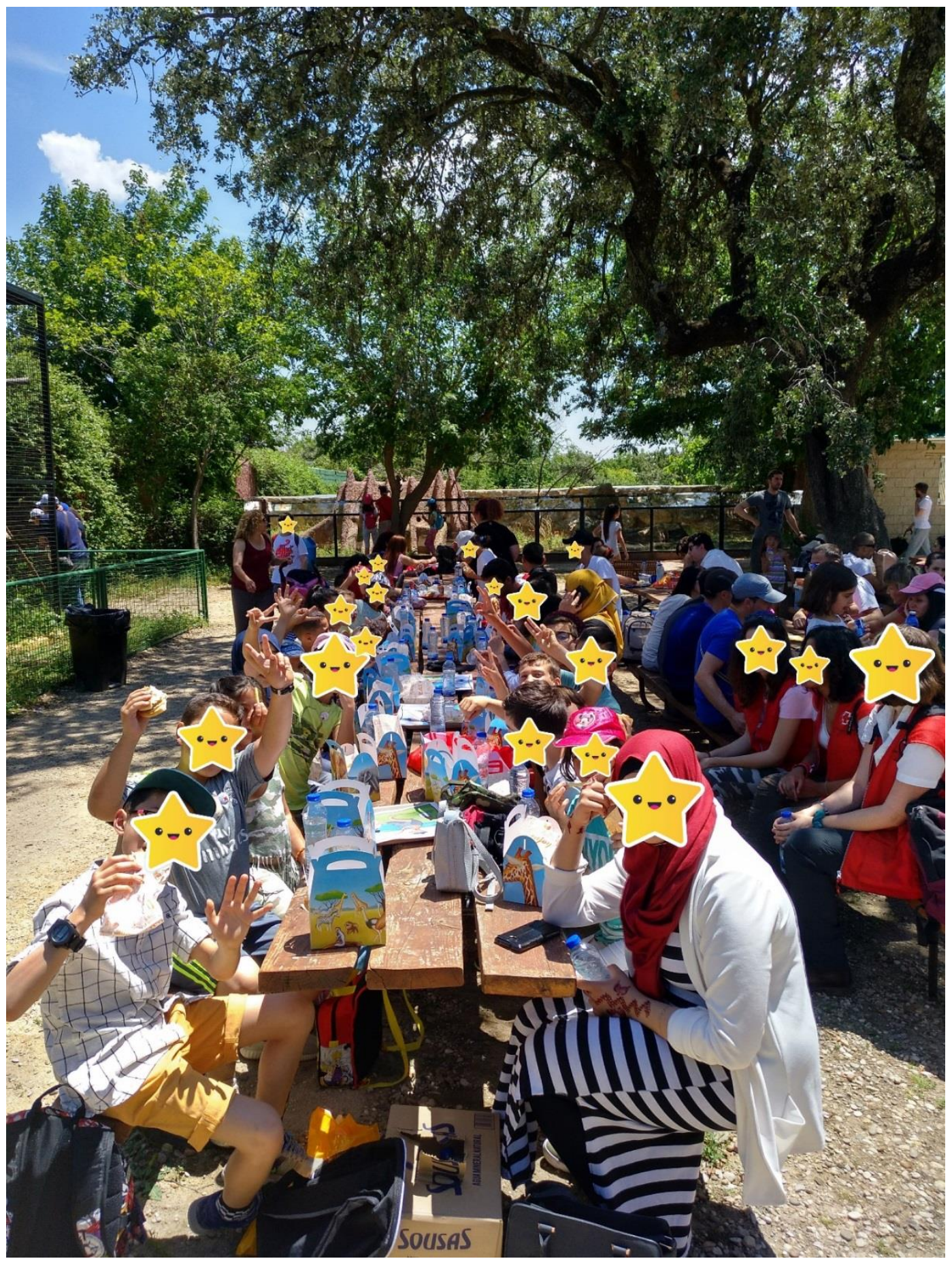

